\title{
Arterial dissection-lentiginosis syndrome
}

INSERM

\section{Source}

INSERM. (1999). Orphanet: an online rare disease and orphan drug data base. Arterial dissection-lentiginosis syndrome. ORPHA:1682

Arterial dissection-lentiginosis syndrome is a rare association syndrome, reported in several members of two families to date, characterized by arterial dissection, occurring at an early age and presenting with a range of manifestations depending on the vascular territory involved (ex. headache, dysphasia, hemiparesis), in association with cystic medial necrosis and multiple lentigines (brown and black in color and mainly affecting the skin of the trunk and extremities). 